\title{
Balloon \\ dacryocystoplasty study in the management of adult epiphora
}

\begin{abstract}
Purpose To determine the efficacy of dacryocystoplasty with balloon dilation in the treatment of acquired obstruction of the nasolacrimal system in adults.

Methods Balloon dacryocystoplasty was performed in 52 eyes of 42 patients under general anaesthetic. A Teflon-coated guidewire was introduced through the canaliculus and manipulated through the nasolacrimal system and out of the nasal aperture. A $4 \mathrm{~mm}$ wide $3 \mathrm{~cm}$ coronary angioplasty balloon catheter was threaded over the guidewire in a retrograde fashion and dilated at the site of obstruction.

Results There was complete obstruction in $30 \%$ of cases and partial obstruction in $70 \%$. The most common site of obstruction was the nasolacrimal duct. The procedure was technically successful in $94 \%$ of cases. The overall re-obstruction rate was $29 \%$ within 1 year of the procedure. There was an anatomical failure rate of $\mathbf{1 7 \%}$ for partial obstruction and $69 \%$ for complete obstruction within 1 year.

Conclusions Balloon dacryocystoplasty has a high recurrence rate. There may be a limited role for this procedure in partial obstructions. Further refinements of the procedure are necessary before it can be offered as a comparable alternative to a standard surgical dacryocystorhinostomy.
\end{abstract}

Key words Balloon dacryocystoplasty, Dacryocystogram, Epiphora, Lacrimal obstruction

Lacrimal obstruction is a common ophthalmic problem and accounts for $3 \%$ of clinic visits. ${ }^{1,2}$ It is secondary to idiopathic chronic inflammation of the lacrimal system in adults leading to stenosis and fibrous obliteration. Treatment options include a surgical dacryocystorhinostomy (DCR), silicon intubation, endonasal endoscopic dacryocystorhinostomy and balloon dacryocystoplasty (DCP). A surgical DCR is the gold standard of treatment with reported success ratess of $89-95 \%$. $^{3,4}$ Reported success rates for balloon DCP are widely variable, ranging from $23 \%$ to $90 \%$. 5

The aim of this study was to determine the efficacy of DCP with balloon dilation in the treatment of acquired obstruction of the nasolacrimal system in adults in our unit.

\section{Materials and methods}

This was a retrospective study between January 1997 and December 1999. The procedure was performed in 52 eyes of 42 patients, i.e. 10 patients had a bilateral procedure simultaneously. There were 32 women and 10 men. The mean age was 58 years (range 18-95 years). The mean duration of symptoms prior to DCP was 30 months with a range of 6 to 120 months. The mean follow-up was 18 months (range 6-34 months).

Patients were asked to grade their epiphora pre- and post-operatively on a scale of 0 to 5 based on Munk's scale: ${ }^{7}$ grade 0, no epiphora; grade 1, requires dabbing less than twice a day; grade 2, requires drying 2-4 times a day; grade 3 requires drying 5-10 times a day; grade 4, requires drying more than 10 times a day; grade 5, constant watering. All patients had constant watering, i.e. grade 5 epiphora, pre-operatively. Each patient had an ophthalmic examination, syringing and probing and a dacrocystogram (DCG) prior to the procedure to determine the site and type of obstruction. There was complete obstruction in $29 \%$ of eyes $(15 / 52)$ and partial obstruction in $71 \%(37 / 52)$ of eyes (Table 1$)$. The most common site of obstruction was in the nasolacrimal duct $(n=37)$. Other sites of obstruction included the junction of the canaliculi $(n=4)$ and the common canaliculus $(n=2)$, and there were multiple stenoses in 9 patients.

DCP was performed under general anaesthetic with a laryngeal mask. A 20-gauge plastic arterial sheath was inserted through the upper or lower punctum into the canaliculus as a guiding cannula for the wire. A 0.018 inch Teflon-coated stainless steel guidewire was then introduced through the canaliculus and gently manipulated down through the lacrimal sac and
S. Fenton

P.E. Cleary

E. Horan

A. Murray

S.L. Ho

G. O'Connor

Department of

Ophthalmology

Cork University Hospital

Cork, Ireland

D. Ryder

Department of Radiology Cork University Hospital

Cork, Ireland

Received: 2 March 2000 Accepted in revised form: 27 July 2000 
Table 1. Sites and type of obstruction by dacryocystogram

\begin{tabular}{lll}
\hline Sites of obstruction & Type of obstruction & Failures $/$ Re-obstructions \\
\hline Nasolacrimal duct $(n=37)$ & Partial $(n=28)$ & 4 \\
Junction of the canaliculi $(n=4)$ & Complete $(n=9)$ & 8 \\
& Partial $(n=1)$ & 0 \\
Common canaliculus $(n=2)$ & Complete $(n=3)$ & 2 \\
Multiple sites of stenosis $(n=9)$ & Partial $(n=1)$ & 0 \\
& Complete $(n=1)$ & 2 \\
Total $(n=52)$ & Partial $(n=6)$ & 0 \\
\hline
\end{tabular}

nasolacrimal duct until the tip of the wire emerged under the inferior turbinate and was then retrieved through the nasal aperture. A $4 \mathrm{~mm}$ wide $3 \mathrm{~cm}$ long deflated angioplasty balloon catheter was then threaded, under fluoroscopic control, over the guidewire in a retrograde fashion into the nasolacrimal apparatus to lie within the site of the obstruction. A radiograph during inflation confirmed correct positioning of the balloon. The balloon was inflated at the site of the obstruction up to 8-13 atmospheres of pressure for 1-2 min and then repeated. A DCG using non-ionic Omnipaque 300 was performed to confirm free passage of contrast through the nasolacrimal system. The balloon catheter was removed inferiorly and the wire superiorly. If there was a canalicular obstruction a smaller $3 \mathrm{~mm}$ wide $1 \mathrm{~cm}$ long coronary angioplasty catheter was used. Topical antibiotics or steroids were not used routinely postoperatively. Patients were discharged on the same day and followed up in the outpatient department.

\section{Results}

The results of the study were viewed in terms of its technical success and its subjective clinical success. A technical success was defined as patency of the nasolacrimal system on a DCG at the end of the procedure. Technically the procedure was successful in 49 of $52(94 \%)$ procedures. There were 3 technical failures. In 1 procedure a false passage was created at the level of the common canaliculus. The other 2 failures had complete obstruction of the nasolacrimal duct preventing advancement of the guidewire and the procedures were abandoned. A surgical DCR was performed on these 3 patients later.

A clinical success was defined as a patient who was symptom free or had less than grade 2 epiphora on Munk's scale 6 months post-operatively. Thirty-five of 49 procedures $(71 \%)$ were clinically successful.

There were 14 failures (29\%). These patients returned within 1 year of the procedure with symptomatic epiphora and required a second procedure. Of these, 5 had a repeat balloon DCP, 3 of whom were functional failures. The remaining 9 patients had a surgical DCR an average of 9 months after the initial DCP. A permanent metallic stent was placed in the nasolacrimal ducts of 2 patients who had a repeat DCP to try to improve longterm patency. Follow-up in this group is of 6 months duration and to date shows clinical success.
Treatment of epiphora by balloon dilation was more successful for partial obstruction than for complete obstruction. Of the 17 failures in total, 11 occurred in association with a complete obstruction and 6 in association with a partial obstruction (Table 1).

The subjective clinical success of this procedure was assessed by a telephone questionnaire to all patients who had one DCP. Patients were asked to grade their epiphora post-operatively using Munk's scale and to say whether the procedure was a success subjectively. Twenty-three of 35 procedures were reported as successful and the remaining 12 were reported as failures.

\section{Discussion}

Becker and Berry first reported dacryocystoplasty in 1989. ${ }^{8}$ Different authors report varying results of DCP. Some of the early reports have small numbers of patients and limited follow-up. In 1990 Munk et al. reported an improvement in symptoms in 13 of 16 patients with a functional obstruction $(80 \%)$ who had DCP with a maximum follow-up of 6 months. ${ }^{7}$ Kumar $^{9}$ reported a clinical improvement in 26 of 31 patients $(83 \%)$ with a similar follow-up of 6 months.

Other studies have larger numbers of patients and longer follow-up. Janssen et al. ${ }^{10}$ reported a long-term patency rate of $70 \%$ in 100 eyes of 80 patients with obstruction at or below the level of lacrimal sac with a mean follow-up of 21 months. Song et al. ${ }^{11}$ reported a success rate of $56 \%$ in 22 of 39 eyes but a recurrence rate of $45 \%$ after 2 months in patients with complete obstruction of the nasolacrimal system.

Lee reported a patency rate of only $23 \%$ after 2 years with partial or complete obstruction in 81 eyes. ${ }^{5}$ We report a series of 52 procedures in 42 patients with partial or complete obstruction. There was an anatomical failure in 17 of $52(32 \%)$ procedures within 1 year. There was an additional 12 of 52 (23\%) functional failures on the basis of a telephone questionnaire. This was an overall failure rate of only $55 \%$ with a mean follow-up of 14 months.

Differences in results of various series may be attributed to patient selection. Selection of patients with partial obstruction below the lacrimal sac may improve success rates. There was a higher failure rate in patients who had complete obstruction compared with those with partial obstruction in the nasolacrimal system. In our series 11 of 16 procedures (69\%) with complete 
obstruction failed. The results of DCP for partial obstruction were better. Six of 36 procedures (17\%) for partial obstruction failed. An additional 12 procedures were reported as functional failures after the telephone questionnaire giving an overall failure rate of 18 of 36 (50\%) for partial obstruction.

Although DCP resolves the obstruction initially, it does not remedy the primary inflammatory process so recurrence of the fibrotic obstruction is likely. This explains the high recurrence rate within the first year in this series. Balloon DCP with subsequent silicon intubation or stent placement should ensure long-term patency and improve success rates. Song et al. ${ }^{12,13}$ treated patients with recurrent obstruction with stents and reported moderate success with recurrence rates between $15 \%$ and $64 \%$. Steinkogler et al. ${ }^{14}$ performed monocanalicular silicon intubation after DCP to ensure permeability of the system and reported success in 6 patients followed for an average of 22 months.

Lee et al..$^{5}$ reported recurrence rates of $45-80 \% 2$ years after DCP and suggested primary stent placement for lacrimal duct obstruction. However, stents can create problems. Stent occlusions may occur due to incrustation of mucoid material or overgrowth of the proximal end of a stent with granulation tissue. ${ }^{13}$ Stents are also expensive. Perry et al. ${ }^{15}$ performed balloon catheter dilation in 15 nasolacrimal duct obstructions using an antegrade insertion technique and performed immediate subsequent silicon intubation. They reported a clinical success rate of $60 \%$ at 6 months follow-up.

Our procedure was performed under general anaesthesia with a laryngeal mask. As an alternative other authors have used local infiltration of the medial canthus and infratrochlear block with $2 \%$ lignocaine, topical benoxinate $0.4 \%$ into the conjunctival fornix, $5 \%$ cocaine spray to the nose and $2-4 \mathrm{mg}$ medazolam for sedation. ${ }^{16}$ Each procedure took $30-40 \mathrm{~min}$ and required costly disposables such as angioplasty catheters and guidewires. Because of these factors it offers no great advantage over a standard DCR.

The high re-stenosis rate is the major limitation of this technique. We report an anatomical failure rate of $17 \%$ for partial obstruction and $69 \%$ for complete obstruction within 1 year of the procedure. There may be a limited role for DCP in partial obstruction of the nasolacrimal system.
In conclusion, the results of balloon dacryocystoplasty in this series are disappointing. The high recurrence rate means that further refinements of this procedure are necessary before it can be offered as a comparable alternative to a standard surgical DCR.

\section{References}

1. Traquair HM. Chronic dacryocystitis: its causation and treatment. Arch Ophthalmol 1941;26:165-80.

2. Duke-Elder S. System of ophthalmology. In: Duke-Elder S, editor. The ocular adnexa, vol 13. London: Henry Kimpton, 1974:675-93.

3. Song HY, Jin $Y H$, Kim KH, Sung KB, Han YM, Cho NC. Nasolacrimal duct obstruction treated nonsurgically with use of plastic stents. Radiology 1994;190:535-9.

4. Massaro BM, Gonnering RS, Harris GJ. Endonasal laser dacryocystorhinostomy: a new approach to nasolacrimal obstruction. Arch Ophthalmol 1990;108:1172-6.

5. Lee JM, Song HY, Han YM, et al. Balloon dacryocystoplasty: results in the treatment of complete and partial obstructions of the nasolacrimal system. Radiology 1994;192:503-8.

6. Janssen AG, Mansour K, Krabbe GJ, van der Veen S, Helder $\mathrm{AH}$. Dacryocystoplasty: treatment of epiphora by means of balloon dilation of the obstructed nasolacrimal duct system. Radiology 1994;193:453-6.

7. Munk PL, Lin DTC, Morris DC. Epiphora: treatment by means of dacryocystoplasty with balloon dilation of the nasolacrimal drainage apparatus. Radiology 1990;177:687-90.

8. Becker BB, Berry FD. Balloon catheter dilatation in lacrimal surgery. Ophthalmic Surg 1989;20:193-8.

9. Kumar EN. Technical note. Non-surgical treatment of epiphora by balloon dacryocystoplasty: the technique. $\mathrm{Br} \mathrm{J}$ Radiol 1995;68:1116-8.

10. Janssen AG, Mansour K, Bos JJ. Obstructed nasolacrimal duct system in epiphora: long term results of dacryocystoplasty by means of balloon dilation. Radiology 1997;205:791-6.

11. Song HY, Ahn HS, Park CK, Kwon SH, Kim CS, Choi KC. Complete obstruction of the nasolacrimal system. I. Treatment with balloon dilation. Radiology 1993;186:367-71.

12. Song HY, Ahn HS, Park CK, Kwon SH, Kim CS, Choi KC. Complete obstruction of the nasolacrimal system. II. Treatment with expandable metallic stents. Radiology 1993;186:372-6.

13. Song HY, Jin YH, Kim JH, et al. Non-surgical placement of a nasolacrimal polyurethane stent: long term effectiveness. Radiology 1996;200:759-63.

14. Steinkogler FJ, Huber E, Kuchar A, et al. Retrograde dilation of postsaccal lacrimal stenosis. Ann Otol Rhinol Laryngol 1994;103:110-4.

15. Perry JD, Maus M, Nowinski TS, Penne RB. Balloon cathether dilation for treatment of adults with partial nasolacrimal duct obstruction; a preliminary report. Am J Ophthalmol 1998;126:811-6.

16. Robinson R, Turner N, Brettle $\mathrm{P}$, et al. The treatment of epiphora with balloon dacryocystoplasty. Eye 1993;7:687-90 